\title{
Seeing eye to eye: social augmented reality and shared decision making in the marketplace
}

\author{
Tim Hilken $^{1}$ (D) Debbie I. Keeling ${ }^{2} \cdot$ Ko de Ruyter ${ }^{3,4} \cdot$ Dominik Mahr $^{1,5} \cdot$ Mathew Chylinski $^{4}$
}

Received: 6 August 2018 / Accepted: 7 August 2019 / Published online: 30 August 2019

(C) The Author(s) 2019

\begin{abstract}
Firms increasingly seek to improve the online shopping experience by enabling customers to exchange product recommendations through social augmented reality (AR). We utilize socially situated cognition theory and conduct a series of five studies to explore how social AR supports shared decision making in recommender-decision maker dyads. We demonstrate that optimal configurations of social AR, that is, a static (vs. dynamic) point-of-view sharing format matched with an image-enhanced (vs. text-only) communicative act, increase recommenders' comfort with providing advice and decision makers' likelihood of using the advice in their choice. For both, these effects are due to a sense of social empowerment, which also stimulates recommenders' desire for a product and positive behavioral intentions. However, recommenders' communication motives impose boundary conditions. When recommenders have strong impression management concerns, this weakens the effect of social empowerment on recommendation comfort. Furthermore, the stronger a recommender's persuasion goal, the less likely the decision maker is to use the recommendation in their choice.
\end{abstract}

Keywords Social augmented reality · Online shopping · Shared decision making · Customer-to-customer communication · Socially situated cognition

Shailendra Jain served as Area Editor for this article.

Tim Hilken

t.hilken@maastrichtuniversity.nl

Debbie I. Keeling

D.I.Keeling@sussex.ac.uk

Ko de Ruyter

ko.de_ruyter@kcl.ac.uk

Dominik Mahr

d.mahr@maastrichtuniversity.nl

Mathew Chylinski

m.chylinski@unsw.edu.au

1 Department of Marketing and Supply Chain Management, Maastricht University, Tongersestraat 53, 6211, LM Maastricht, The Netherlands

2 University of Sussex Business School, University of Sussex, Brighton BN1 9SL, UK

3 King's Business School, King's College London, London WC2B 4BG, UK

4 UNSW Business School, University of New South Wales, Sydney, NSW 2052, Australia

5 Service Science Factory, Maastricht University, 6211 LN Maastricht, The Netherlands

\section{Introduction}

Many firms, including Amazon, IKEA, and L'Oreal, already rely on augmented reality (AR) to enhance the online experience of their customers (Porter and Heppelmann 2017). By projecting virtual content (e.g., 3D furniture items from an online shop) into the physical environment (e.g., a customer's living space), ${ }^{1}$ AR lets customers get a better feel for products, and this makes them feel more comfortable with purchase decisions (Heller et al. 2019; Hilken et al. 2017). Yet, aside from ratings and reviews, when shopping online customers commonly rely on the advice of friends and family (Zhu et al. 2010), which they expect to be able to obtain without having to switch between channels or apps (Brynjolfsson et al. 2013). Current AR apps (e.g., Converse's Shoe Sampler) only allow customers to share and invite comments on screenshots of AR content posted on third-party social media, which makes getting advice from peers cumbersome and far from seamless. However, recent innovations (e.g., Snapchat's Shoppable AR) are facilitating within-app sharing and product

\footnotetext{
${ }^{1}$ AR thus differs from virtual reality (VR) technology that immerses the customer into a fully artificial environment (e.g., a virtual shopping mall or virtual test-drive for an automobile).
} 
purchasing, thus ushering in new AR applications that support engagement and shared decision making amongst customers (Hilken et al. 2018; Scholz and Smith 2016). We identify this new class of AR as social AR, which we define as a technology that enables two or more users to communicate by sharing and virtually enhancing a common view of the physical environment. For example, with Akzo Nobel's Visualizer, customers seeking to buy paint to redecorate their home can share a photo or video of their living room to invite purchase advice from others. Within the shared visual, friends and family can experiment with color designs and ultimately convey a recommendation regarding what color paint to buy, not only as a written message, but also directly through an AR-enhanced visual.

As customers start to engage in shared decision making with social AR, a fundamental premise is that both recommenders and decision makers feel comfortable with providing and accepting advice through the technology. This premise has not been systematically addressed in extant research and more insights are needed into the process and outcomes of using social AR (Hilken et al. 2018; de Ruyter et al. 2018). Relatedly, research offers little guidance on optimal AR configurations of sharing formats (photo or video) and communication modes (text and/or images) for firms wishing to support shared decision making (Javornik 2016; de Ruyter et al. 2018). Addressing these gaps in the knowledge base is pertinent as customer adoption and conversion rates for AR remain incremental and/or speculative (ARtillry 2019; Gartner 2018). Managers need a better understanding of how to enable shared experiences in social AR (Scholz and Smith 2016), such that customers embrace the technology, ultimately culminating in favorable returns on investments.

We address this need by building on marketing literature that regards customer decision making as a staged and social process (Batra and Keller 2016; Harmeling et al. 2017; Zhang et al. 2018). To identify relevant mechanisms in this process, we utilize socially situated cognition theory (Semin and Smith 2013), which posits that people commonly rely on each other's support to complete a task. Accordingly, in shared decision making, a recommender relies on the decision maker to effectively share his or her point of view (POV; Zhu et al. 2010). In turn, a decision maker relies on the recommender to effectively convey a product recommendation, to reduce decision difficulty and empower them in their product choice (Broniarczyk and Griffin 2014). On this basis, we offer an in-depth exploration of how social AR can support the process of shared decision making amongst customers and lead to marketing-relevant outcomes for firms. To the best of our knowledge, our research is the first to define and comprehensively study social AR. In doing so, we make three main contributions.

First, we draw on socially situated cognition theory (Semin and Smith 2013) to conceptualize the key features of social
AR as (1) POV sharing formats (static photo vs. dynamic video), which vary in the extent to which a recommender can take the decision maker's perspective, and (2) communicative acts through which a recommendation can be conveyed (text-only vs. image-enhanced; Villarroel Ordenes et al. 2018). We use Akzo Nobel's innovative Visualizer application to empirically test how optimal configurations of POV sharing and communicative acts improve recommenders' comfort with giving purchase advice and, in turn, influence the decision maker's choice.

Second, we seek to understand the use of social AR as a process by specifying a key mediating mechanism, that is, the experience of social empowerment on both sides of the dyad. When social AR is optimally configured, recommenders likely feel that they are better able to provide a recommendation, such that they gain a greater sense of making a positive difference in another person's decision (Hanson and Yuan 2018). This sense of empowerment should not only increase comfort with providing a product recommendation but also stimulate recommenders' own desire for the product and trigger positive intentions towards the app (e.g., Fuchs et al. 2010). Equally, receiving a recommendation through social AR should also lead to a sense of social empowerment amongst decision makers. This implies that they would feel supported in their choices (Ouschan et al. 2006), which might increase the likelihood of using a recommendation in their decision.

Third, we identify two important boundary conditions associated with recommenders' communication motives. These are important for managers to take into account when deciding to deploy social AR applications. We acknowledge that there may be concerns about making a bad impression (Berger 2014), for instance due to a poor recommendation, and this could interfere with recommenders' comfort with assisting in another person's decision. Hence, we identify how the strength of a recommender's impression management concerns might attenuate the positive effect of social empowerment on recommendation comfort. Furthermore, from the other side of the dyad, a recommender's advice may be viewed as overbearing and come across as trying too hard to persuade a decision maker towards a specific option (Fransen et al. 2015). Persuasion is a self-serving motive (Berger 2014), which is at odds with the pro-social focus of providing a recommendation to empower another person in their choice. Thus, we study how a recommender's persuasion goal might suppress the positive impact of social empowerment on the decision maker's choice.

To establish these contributions, we outline a framework of shared decision making and hypothesize how social AR supports the customers involved at each stage. We conduct a series of studies that emulate the dyadic interaction between two "purchase pals" - that is, we study shared decision making amongst recommenders and decision makers who are close friends. In Study 1, we test how configurations of 
POV sharing formats and communicative acts shape recommenders' comfort with providing a product recommendation. We investigate social empowerment as the underlying mediator and a recommender's impression management concerns as a moderator in Studies 2 and 3, respectively. Then, in Study 4, we assess how the different communicative acts through which a decision maker can receive a recommendation influence actual choice, and whether there is potential attenuation due to the recommender's persuasion goal. In Study 5, we test how the experience of social empowerment may stimulate recommenders' own desire for a product and spill over to positive behavioral intentions. We conclude with theoretical and managerial implications and identify a number of directions for further research.

\section{Conceptual background}

\section{Shared decision making amongst customers}

Extant marketing literature emphasizes that customer decision making is a multi-stage process (Batra and Keller 2016) that oftentimes involves the exchange of information and decision support with others (Harmeling et al. 2017; Zhang et al. 2018). Apart from online reviews and ratings, many customers consider friends and family as trustworthy advisors (Deloitte 2016). They share both their offline and online shopping journeys with these "purchase pals," who assist them in making a purchase decision (Hartman and Kiecker 1991; Zhang et al. 2018; Zhu et al. 2010). We represent this dyadic, shared decision making process in four key stages (Fig. 1), delineating decision maker and recommender roles (Blazevic et al. 2013). In stage 1, a decision maker requests assistance from a recommender and shares their POV in the decision (e.g., their view of the living room that is to be redecorated). In stage 2 , the recommender searches different product options and communicates their recommended choice to the decision maker (e.g., which color paint to choose). In stage 3 , the decision maker considers whether to incorporate that recommendation into their final decision. In stage 4 , the recommender may experience spillover effects from assisting the decision maker (e.g., a desire to redecorate their own home).

\section{Key features of social AR: a socially situated cognition perspective}

We aim to identify how managers might optimally configure social AR so that it can support this multi-staged shared decision making process. Socially situated cognition theory posits that people have a natural tendency to share their everyday experiences with others to make relevant, collective judgments or decisions (Smith and Collins 2009). Others have unique resources (e.g., a unique point of view on a decision or specific product knowledge), and people can lean on those resources to empower their choices (Semin and Smith 2013). These key principles enable us to conceptualize two features of social AR.

First, effective dyadic communication requires people to share a common POV (Tuomela 2007). This entails the ability to reenact another person's movements with one's own body, to gain contextual information and understand the other's circumstances (Semin and Smith 2013). Marketers can leverage virtual technologies that allow customers to share a common perspective during online shopping (Zhu et al. 2010). Social AR uniquely enables decision makers to capture and visually share their POV in a decision context with a recommender. We thus discern $P O V$ sharing as a requisite key feature of social $\mathrm{AR}$ - that is, the extent to which a recommender can move virtually through the decision maker's space to take this viewpoint and get a feel for their environment. Visual POV sharing can be done through dynamic and static formats. Dynamic (video) formats better enable customers to simulate the corresponding real-world experience compared with static (photo) formats (Rosa and Malter 2003), so they should enable more effective POV sharing.

Second, customers may use different communicative acts - that is, overt forms of communication for supporting or cooperating with another person (Reich 2011), for example providing a recommendation in a purchase decision. Currently, online customers mainly exchange product recommendations through text-only acts, for example in social

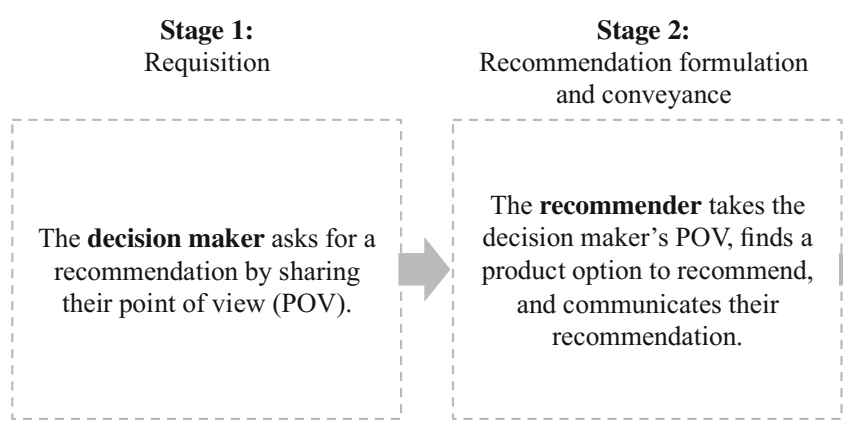

Fig. 1 Staged process model of shared decision making

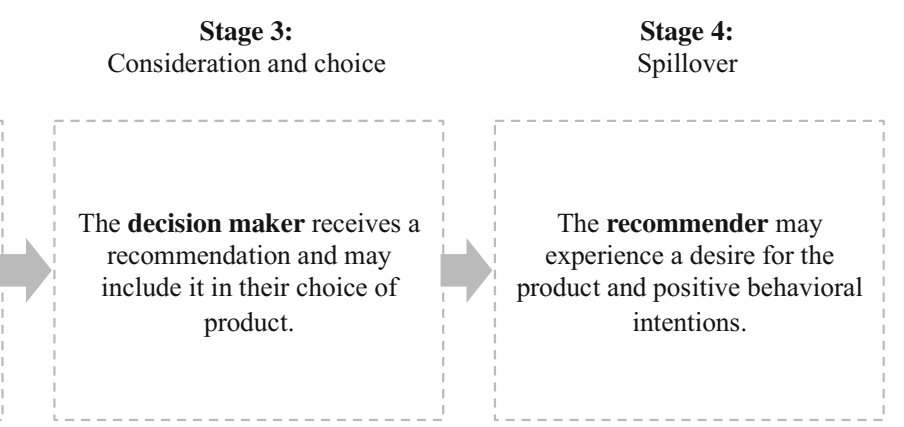


media comments, posts in online communities, and product reviews (Villarroel Ordenes et al. 2018). Text-only acts tend to be abstract and effortful to produce, and may require the communication partners to recode information from a visual to a verbal modality (Berger 2014; Wyer et al. 2008). A key feature of social AR is that it enables image-enhanced acts, where customers can exchange information by projecting virtual content (e.g., product representations) into shared POV visuals, in addition to providing written text. Akzo Nobel's Visualizer application enables recommenders to convey their recommendation by projecting a specific wall color into a shared photo or video, rather than just describing it verbally. Image-enhanced acts, thus, help customers exchange information in realistic representations (Geise and Baden 2015) that can be understood intuitively (Townsend and Kahn 2014).

\section{Hypotheses development}

\section{Stages 1 and 2: Requesting, formulating, and conveying the recommendation}

For recommenders, giving advice entails comprehending another person's POV, and selecting and proposing a specific choice back to the decision maker. These activities can be effortful, particularly in online settings (King et al. 2014), and expose the recommender's proposed choice to social judgment from the decision maker. We argue that it is important to study how social AR might elicit recommendation comfort, which we define as a recommender's sense of ease related to proposing a specific choice to another customer (cf. Parker et al. 2016). Feeling comfortable with one's (recommended) choices positively influences the overall evaluation of an experience and subsequent behavioral intentions (Parker et al. 2016). We propose that distinct configurations of POV sharing (static vs. dynamic) and communicative acts (text-only vs. image-enhanced) will differentially enhance recommendation comfort. We expect such differences as combining multiple communication features can result in antagonistic effects (Kolsarici and Vakratsas 2018).

Configuring a static photo with a text-only recommendation is likely to be sub-optimal. A recommender that receives a static photo of, for example, a friend's living room, may struggle to share the decision maker's POV because a photo does not support an experience of movement and hence taking the other person's perspective (Semin and Smith 2013). Then it is difficult to provide a text-only recommendation to convey how a specific wall color looks in the room, as the recommender needs to mentally shift their perspective through the room to formulate a written description in context (Jiang et al. 2014). However, being able to project a virtual representation of the color onto a static photo (i.e., an image-enhanced act) may compensate for the poorer POV sharing format. This is because the image-enhanced act conveys a contextualized recommendation as a concrete, real-world image (Geise and Baden 2015), reducing the cognitive effort needed to make the recommendation (Porter and Heppelmann 2017). Ease and contentment in a decision experience, such as making a recommendation, are conducive to feelings of comfort (Parker et al. 2016). Thus, a recommender should derive comfort from the ability to provide a choice recommendation via an imageenhanced (vs. a text-only) act when configured with a static photo.

Conversely, a video helps the recommender to dynamically take the decision maker's POV, so they no longer need to mentally shift perspectives to different viewpoints. This sense of presence in AR-enhanced environments provides customers with more contextual information, which facilitates controlled, sequential processing, as is required for written communication (He et al. 2018). Dynamic POV sharing formats, thus, might complement a recommender's ability to communicate with text-only acts and still provide a sense of comfort. In sum, the potential differential impacts of configuring static (vs. dynamic) POV sharing formats with text-only (vs. image-enhanced) acts will likely result in an antagonistic interaction effect on recommendation comfort.

H1: There is an antagonistic interaction effect of configurations of POV sharing formats and communicative acts on recommendation comfort.

Previous research suggests that providing a recommendation is a pro-social behavior (Hennig-Thurau et al. 2004), which can manifest as a feeling of social empowerment (Hanson and Yuan 2018). For recommenders, we define social empowerment as a sense that they are making a positive difference in another person's purchase decision (Hanson and Yuan 2018). Optimal configurations of social AR should increase a recommender's perceived ability to make a meaningful contribution that benefits the decision maker, and thus lead to social empowerment. Indeed, research has demonstrated that product visualizations empower customers by helping them creatively articulate their ideas (Füller et al. 2009). Perceived social empowerment should then have positive outcomes for recommenders, in that helping others and feeling a positive impact increases satisfaction (Prentice et al. 2016) and promotes positive affect (Koopman et al. 2016). Such benefits may create a sense of comfort (Parker et al. 2016), specifically with recommending a choice to another customer. As such, we propose that social empowerment explains the interaction effect of configurations of social AR on recommendation comfort.

H2: The interaction effect of configurations of POV sharing formats and communicative acts on recommendation comfort is mediated by social empowerment. 
We hypothesize that social empowerment is the mediating mechanism for recommender comfort, but also consider an alternative explanation. Recent research suggests that optimal configurations of AR features (e.g., virtual sharing and enhancement of products) can stimulate personal, self-focused engagement with choosing a product (Scholz and Duffy 2018; Scholz and Smith 2016). Personal engagement in a choice is distinct from a pro-social motivation for making a recommendation (Hennig-Thurau et al. 2004) and, in turn, might provide recommenders with a sense of comfort by facilitating the choice task and increasing the perceived appeal of the product options (Parker et al. 2016). We thus investigate personal choice engagement as an alternative mediator.

It is also likely that not all recommenders derive equal comfort with contributing to a purchase decision, and so, we account for individual motivations for providing a recommendation. Whilst recommenders might seek to make a positive difference for another person (Hennig-Thurau et al. 2004), they might also be concerned about the impression they make (Berger 2014; Dillard et al. 1989; Schrader and Dillard 1998). Impression management concerns are common in online settings (Oh and LaRose 2016) and describe a customer's desire to avoid negative self-presentations (Berger 2014). People vary in the extent to which they are motivated to avoid making negative impressions (Hewitt et al. 2003). In shared decision making with social AR, a recommender might be concerned that their recommendation is considered an inappropriate choice and, hence, create a bad impression. We previously hypothesized that optimal configurations of social AR facilitate providing a recommendation, which may give recommenders a heightened sense of making a positive difference in another customer's purchase decision. Such a perceived increase in impact makes people feel more vulnerable to judgment, with an increased risk of being blamed for a choice that others do not like (Bartling and Fischbacher 2012). For a recommender with strong impression management concerns, feeling a greater impact on a decision thus may cause feelings of anxiety, which diminish comfort with the experience (Parker et al. 2016).

H3: The positive relationship between social empowerment and recommendation comfort is attenuated by the strength of the recommender's impression management concerns.

\section{Stage 3: Consideration and choice by the decision maker}

In stage 3, decision makers receive a recommendation that they can use to reduce their decision difficulty and search efforts, as it enables them to limit their choices to a smaller set of alternatives that others have already evaluated (Broniarczyk and Griffin 2014). Thus, a key concern is whether a recommendation can be easily comprehended so that it facilitates making a choice (Adjei et al. 2010). Accordingly, in this stage of the shared decision making process, we focus on investigating how social AR's different communicative acts (text-only vs. image-enhanced) enable decision makers to incorporate a recommendation into their decision making, and how this is reflected in their actual choice. $^{2}$

Consistent with our conjecturing in $\mathrm{H} 1$, imageenhanced (vs. text-only) acts may facilitate shared decision making when customers find it difficult to share a common POV, not only by enhancing the recommender's sense of comfort, but also by facilitating the decision maker's choice. That is, receiving a visual recommendation (e.g., an image of a new wall color applied to the living room) relieves the decision maker of the effort needed to recode a written description into a mental model, enabling them to interpret the image with greater ease (Geise and Baden 2015; Wyer et al. 2008). Further, customers prefer visual depictions of choice options (Townsend and Kahn 2014) and find images more compelling than written arguments (Jeong 2008). Thus, image-enhanced acts should make the recommendation easier to comprehend and integrate into the decision, resulting in choices that are aligned with the recommendation.

We anticipate that this effect also relies on a sense of social empowerment. For decision makers, we define social empowerment as the sense that another person is making a positive difference in their decision making. This sense of empowerment arises from the receipt of meaningful information that makes a positive contribution to well-being or task completion (Ouschan et al. 2006; Wathieu et al. 2002). Recommendations that include product visualizations promote understanding, which facilitates a sense of empowerment (Füller et al. 2009) and, thus, promotes trust and commitment to the empowering party (Ouschan et al. 2006). In consequence, the likelihood that the decision maker incorporates the recommendation in their choice should increase.

H4: For a decision maker, image-enhanced (vs. text-only) acts have a stronger impact on choice, due to a heightened feeling of social empowerment.

As previously hypothesized, recommenders may have other communication motives than a pro-social motivation. Independent of a recommender's impression management concerns, he or she might be motivated by a

\footnotetext{
${ }^{2}$ To isolate the effects of the different communicative acts on decision makers' consideration and choice, we focus on a shared decision making process in which the decision maker initially shared their POV through a static photo. Customers prefer using photos to capture experiences (Diehl et al. 2016) and most visuals on social media are currently shared in photo, rather than video, formats (Newswhip 2017).
} 
persuasion goal, which, through synthesizing insights from previous research (Berger 2014; Dillard et al. 1989), we define as a self-serving motive to bring about behaviour in another person that is consistent with one's own desires. There are significant differences in the extent to which people are motivated by a persuasion goal (Schrader and Dillard 1998). Pertinent to understanding shared decision making with social AR is how a recommender's persuasion goal may influence the decision maker's perceptions of social empowerment and resulting choice. Persuasion is a self-serving motive and thus contradicts the pro-social nature of social empowerment. Decision makers expect to receive support from others in their purchase decisions (Zhu et al. 2010), but if they communicate with a recommender who has a strong persuasion goal, the perceived impact on the decision may appear overbearing or infringe on the decision maker's sense of social empowerment. When decision makers infer a persuasion motive, this negatively influences evaluations of the source (Campbell and Kirmani 2000); decision makers also dismiss or discount information that is considered too pushy or insincere (Fransen et al. 2015), as it is no longer considered a positively empowering influence. Accordingly, a decision maker should be less likely to incorporate a recommendation from a recommender with a strong persuasion goal.

H5: The strength of a recommender's persuasion goal attenuates the effect of social empowerment on the decision maker's choice.

\section{Stage 4: Spillover effects for the recommender}

For recommenders, previous research demonstrates positive spillover effects from supporting another customer in a purchase decision. For instance, Hanson and Yuan (2018) show that a sense of social empowerment from sharing a coupon increases purchase intentions for the recommended product category on the side of the sharer. Furthermore, feelings of empowerment in new product decisions (e.g., from using virtual technology to submit product ideas and suggestions) increase customers' behavioral intentions towards the facilitator of empowerment, including purchase (Fuchs et al. 2010), future participation (Füller et al. 2009), and positive WOM (Fuchs and Schreier 2011). We thus posit that inviting customers to provide recommendations through social AR and the resulting feeling of social empowerment has marketing-relevant spillover effects, in the form of stimulating desire for the product as well as positive usage and WOM intentions towards the social AR application.
H6: Social empowerment increases (a) a recommender's desire for a product, and intentions to (b) use and (c) spread positive WOM about the social AR application.

\section{Analytical strategy}

We empirically test these hypotheses in a series of studies (Fig. 2), ${ }^{3}$ in which we leverage Akzo Nobel's Visualizer application. ${ }^{4}$ We begin by exploring how social AR may support recommenders. Participants receive a photo or video of a room (stage 1), in which they can virtually try different wall colors, then make recommendations (stage 2). In Study 1, we manipulate POV sharing formats and communicative acts to assess their joint effects on recommendation comfort (H1). In Study 2, we investigate social empowerment as an underlying mediator (H2), and, in Study 3, we examine a recommender's impression management concerns as a boundary condition (H3). Moving to stage 3, we vary the study design to pair participants in recommender-decision maker dyads. In Study 4, decision makers use social AR to receive a recommendation from another participant, then make a choice. We investigate the effects of different communicative acts on the decision maker's choice (H4), while also exploring the recommender's persuasion goal as a boundary condition (H5). Finally, we turn to stage 4. In Study 5, we test whether recommenders experience a desire for the product and form positive behavioral intentions as a result of providing a recommendation through social AR (H6a-c).

\section{Study 1}

\section{Design and procedure}

To investigate the interaction effect between POV sharing formats and communicative acts, we sought a sample of younger customers, who represent the early adopter market for ARenabled shopping (DigitalBridge 2017). We recruited 92 participants between 21 and 34 years of age from a large public university, who received course credit for attending a lab session. To create a realistic decision making scenario, we modeled a shared decision, in which all participants were assigned the role of a recommender. The scenario asked participants to make a recommendation to a friend who had to choose a new wall color for a university education room. To ensure participants understood and engaged in the scenario,

\footnotetext{
$\overline{3}$ Throughout our studies we use the PROCESS macro by Hayes (2013) because it allows for bootstrap-based inference of our hypothesized conditional effects (H1), indirect effects ( $\mathrm{H} 2$ and $\mathrm{H} 4)$, and conditional indirect effects ( $\mathrm{H} 3$ and $\mathrm{H} 5$ ) with a consistent method of analysis. It also produces results equivalent to an analysis of variance for the focal interaction effect.

${ }^{4} \mathrm{https}: / /$ www.dulux.co.uk/en/articles/dulux-visualizer-app.
} 


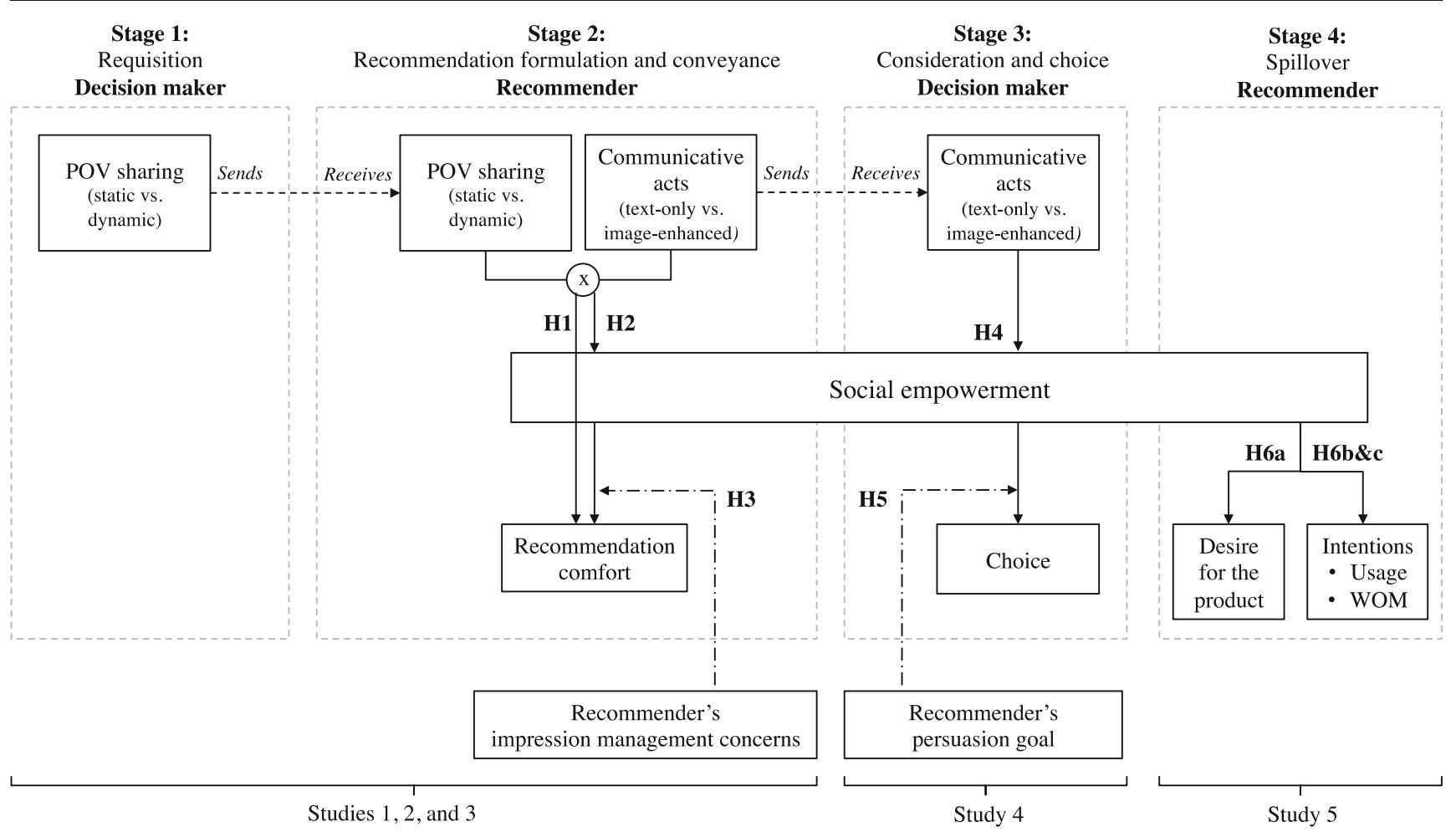

Fig. 2 Staged process model of shared decision making with social AR

we included an attention check ("Which decision, as described in the scenario above, is your friend currently facing?") and asked them to think of an actual friend and describe her or him with three adjectives. Using the AR visualizer application on a tablet PC, the participants could then search for and recommend a specific color. Finally, they completed a computerbased survey. All studies used the same pre-specified quality criteria. We excluded participants from further analysis if they experienced technical difficulties with the application (8), did not understand the scenario, or did not provide a recommendation (4). We thus obtained a final sample of 80 participants (41 women, 39 men) in a 2 (static vs. dynamic POV sharing) $\times$ 2 (text-only vs. image-enhanced acts) between-subjects design.

To manipulate the POV sharing format, the AR visualizer application provided either a (static) photo or a (dynamic) video of the room to be redesigned. The information contained in both formats was identical; it displayed the same section of the room, but in the video condition, participants could dynamically move their viewpoint by using a scrollbar. All participants could use the application to project colors virtually onto the walls. After they had decided on a color, we manipulated how participants could communicate this recommendation, that is, either by sending a written message (text-only) or providing a visual representation of the color in the room in addition to the written message (image-enhanced). (See Appendix 1 for the experimental procedure, stimulus materials, and manipulations).

\section{Measures}

To measure participants' recommendation comfort, we adapted a five-item decision comfort scale from Parker et al. (2016) to refer to comfort with recommending a specific color to another person (e.g., "Although I don't know if this color is the best, I feel perfectly comfortable with the choice I recommended to my friend"; $\alpha=.89$ ). Participants responded to the measure on a seven-point Likert scale ("strongly disagree" $=1$ to "strongly agree" $=7$ ). The items for all constructs are in Appendix 2.

\section{Results}

We used the PROCESS macro (Hayes 2013, Model 1) to test the effects of POV sharing ( static $=0$, dynamic $=1$ ), communicative acts (text-only $=0$, image-enhanced $=1$ ), and their interaction on recommendation comfort. In support of H1, we found a significant antagonistic (negative) POV sharing $\times$ communicative acts interaction effect on recommendation comfort $(\beta=-.80, \mathrm{t}(76)=-2.00, p=.049)$. Further, imageenhanced acts had a significant positive effect $(\beta=.59$, $\mathrm{t}(76)=2.04, p=.045)$, and dynamic POV sharing had a marginally significant positive effect $(\beta=.53, \mathrm{t}(76)=1.81$, $p=.075$ ). The conditional effects analysis partially supports our specific predictions (Fig. 3). If participants received a photo (static POV sharing), the ability to convey their recommendation through an image-enhanced act increased their 
Fig. 3 Study 1: Effects of imageenhanced or text-only acts with static or dynamic POV sharing on recommendation comfort

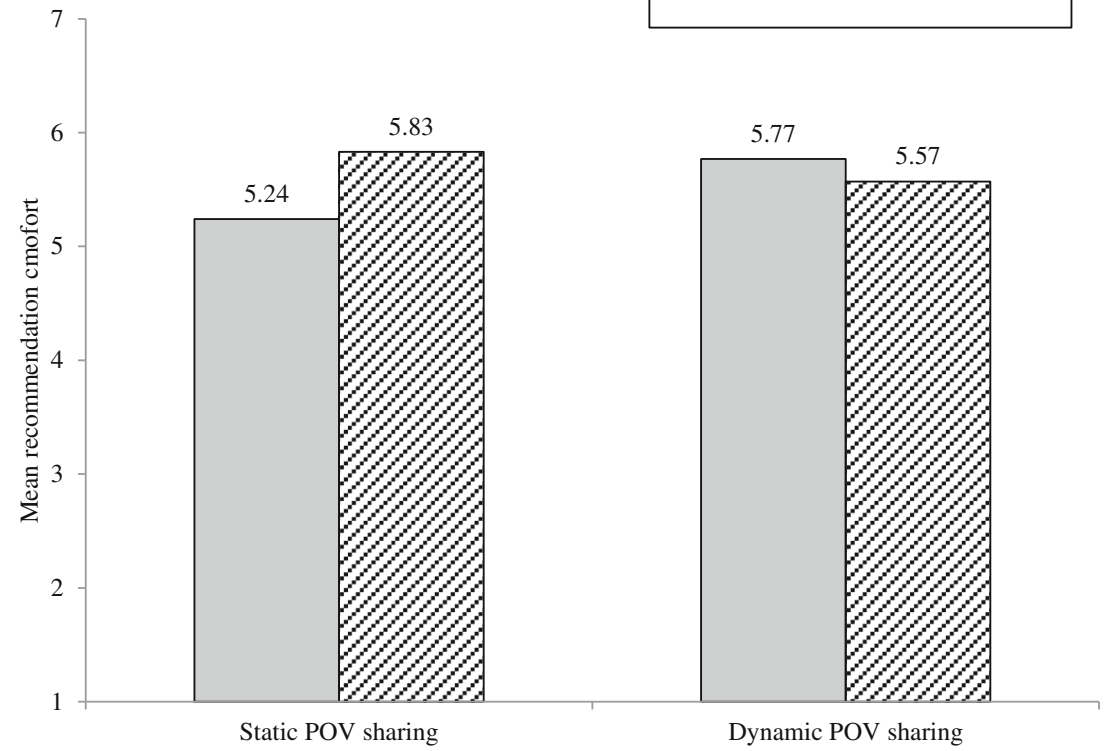

recommendation comfort $\left(\mathrm{M}_{\text {Text }}=5.24, \mathrm{M}_{\text {Image }}=5.83\right.$, $\mathrm{t}(76)=2.04, p=.045)$. Participants who received a video (dynamic POV sharing) indicated greater recommendation comfort when they conveyed their recommendation through a text-only act, though this effect did not reach statistical significance $\left(\mathrm{M}_{\text {Text }}=5.77, \mathrm{M}_{\text {Image }}=5.57, \mathrm{t}(76)=-.74, p=.460\right)$.

\section{Discussion}

These results provide initial insights into how firms might configure social AR applications to enable recommenders to contribute comfortably to a shared decision. Consistent with $\mathrm{H} 1$, we find an antagonistic interaction effect between POV sharing formats and communicative acts on recommendation comfort. With a static photo, it is difficult for the recommender to take the decision maker's POV, so image-enhanced acts can compensate for the lack of POV sharing by enabling ARbased product visualization in the decision context. As a result, the recommender feels more comfortable with making a recommendation. In contrast, if the recommender can dynamically take the decision maker's POV, because the AR content includes video, equivalent comfort results from conveying recommendations through either a text-only or imageenhanced act. Thus, dynamic POV sharing appears to complement written communication. Although these optimal configurations may provide the recommender with a sense of comfort, we anticipate that they also need to feel they are making a positive difference in another customer's decision making (H2). We therefore turn to social empowerment as an underlying mechanism in Study 2.

\section{Study 2}

We used Akzo Nobel's Visualizer, with the desktop version of the application, to test whether social empowerment mediates the relationship between optimal configurations of social AR and recommendation comfort (H2). To substantiate this hypothesized mediation, we also sought to rule out a recommender's personal choice engagement as an alternative mediator.

\section{Design and procedure}

The experimental procedure, AR application, and manipulations were the same as in Study 1. We randomly assigned participants to one of four conditions in the 2 (static vs. dynamic POV sharing) $\times 2$ (text-only vs. image-enhanced acts) between-subjects design. Extending the analysis to a larger population of customers, we recruited 298 participants through Amazon MTurk, in exchange for a small payment. Participants were between 19 and 68 years of age. We excluded participants who used an operating system incompatible with the application (33), reported technical difficulties (22), did not use the app (1), did not understand the scenario and/or provide a recommendation (18). The final sample consisted of 224 participants (140 women, 84 men).

\section{Measures}

To measure social empowerment, we adapted the six-item scale from Hanson and Yuan (2018) to fit the study context (e.g., "I feel that my recommendation made a positive 
difference in my friend's decision making"; anchored at $1=$ "strongly disagree" and $7=$ "strongly agree"). The scale exhibited good internal consistency $(\alpha=.94)$. For participants' choice engagement, we used a 14-item semantic differential scale (e.g., "meaningful-meaningless" as anchors on 7-point scales; $\alpha=$.96; Bruner 2009; Mathmann et al. 2017). As the dependent variable, we included the recommendation comfort measure from Study $1(\alpha=.78)$. The measures are listed in Appendix 2.

\section{Results}

Manipulation checks We conducted a thorough review of socially situated cognition (e.g., Semin and Smith 2013) and linguistics (e.g., Villarroel Ordenes et al. 2018) literature to develop a set of items that are consistent with our conceptualizations of POV sharing and communicative acts. Specifically, four items distinguish image-enhanced (vs. text-only) acts (e.g., "Using the app allowed me to show my friend how my recommended color fits the room"), and five items capture the extent to which participants could share another person's POV by replicating their movements (e.g., "Using the app allowed me to move through the room as my friend would"). We tested both these measures in a separate study on Amazon MTurk with 183 participants (19 to 71 years; 110 women, 73 men), for which the study design and procedure matched that of the main Study 2. Participants rated all items, as listed in Appendix 2, on seven-point Likert scales ( $1=$ "strongly disagree" to $7=$ "strongly agree"). The items demonstrated strong internal consistency $\left(\alpha_{\mathrm{POV}}=.86 ; \alpha_{\text {Communicative }}=.95\right)$, and both manipulations worked as intended. Participants in the image-enhanced acts condition indicated a greater ability to convey their recommendation visually $\left(\mathrm{M}_{\text {Text }}=5.15, \mathrm{M}_{\text {Image }}=6.17\right.$, $\mathrm{t}(153)=-4.66, p<.001)$; those who received a video signaled their enhanced ability to share the POV of the decision maker $\left(\mathrm{M}_{\text {Photo }}=4.83, \mathrm{M}_{\text {Video }}=5.50, \mathrm{t}(181)=-3.80\right.$, $p<.001)$.

Moderated mediation analysis Table 1 shows the results of our analysis in the PROCESS macro (Hayes 2013, Model 8). Consistent with Study 1 and supporting H2, there was a significant antagonistic (negative) POV sharing $\times$ communicative acts interaction effect on social empowerment ( $\beta=-.77, p=.005$, Fig. 4a). The interaction term also predicted choice engagement in the second mediator model ( $\beta=-.66, p=.032)$. In the dependent variable model, social empowerment predicted recommendation comfort ( $\beta=.58, p<.001)$, but choice engagement $\operatorname{did} \operatorname{not}(\beta=$ $-.01, p=.85)$, ruling out this alternative mediator. Bootstrapping with 5000 samples for conditional indirect effects further supports H2 (Fig. 4b). For participants who received a photo, conveying the recommendation via an image-enhanced act produced a significant positive indirect effect through social empowerment on recommendation

Table 1 Study 2: regression results

\begin{tabular}{|c|c|c|c|}
\hline Independent variables & Social empowerment & Choice engagement & Recommendation comfort \\
\hline Constant & $\begin{array}{l}5.22 * * \\
(.12)\end{array}$ & $\begin{array}{l}5.04 * * \\
(.14)\end{array}$ & $\begin{array}{l}2.58^{* *} \\
(.30)\end{array}$ \\
\hline POV sharing & $\begin{array}{l}.32 \dagger \\
(.19)\end{array}$ & $\begin{array}{l}.26 \\
(.21)\end{array}$ & $\begin{array}{l}.08 \\
(.15)\end{array}$ \\
\hline Communicative acts & $\begin{array}{l}.41 * \\
(.18)\end{array}$ & $\begin{array}{l}.36 \dagger \\
(.20)\end{array}$ & $\begin{array}{l}-.07 \\
(.14)\end{array}$ \\
\hline POV sharing $\times$ communicative acts & $\begin{array}{l}-.77 * * \\
(.27)\end{array}$ & $\begin{array}{l}-.66^{*} \\
(.31)\end{array}$ & $\begin{array}{l}.09 \\
(.22)\end{array}$ \\
\hline Social empowerment & - & - & $\begin{array}{l}.58 * * \\
(.07)\end{array}$ \\
\hline Choice engagement & - & - & $\begin{array}{l}-.01 \\
(.06)\end{array}$ \\
\hline $\mathrm{R}^{2}$ & .04 & .02 & .35 \\
\hline MSE & .99 & 1.29 & .61 \\
\hline $\mathrm{F}$ & $2.92 *$ & 1.69 & $23.82 * *$ \\
\hline $\mathrm{df}$ & 3,220 & 3,220 & 5,218 \\
\hline
\end{tabular}

The numbers in parentheses are standard errors. This table provides unstandardized coefficients

Significance based on two-tailed tests: $* * p<.01, * p<.05, \dagger p<.1$ 


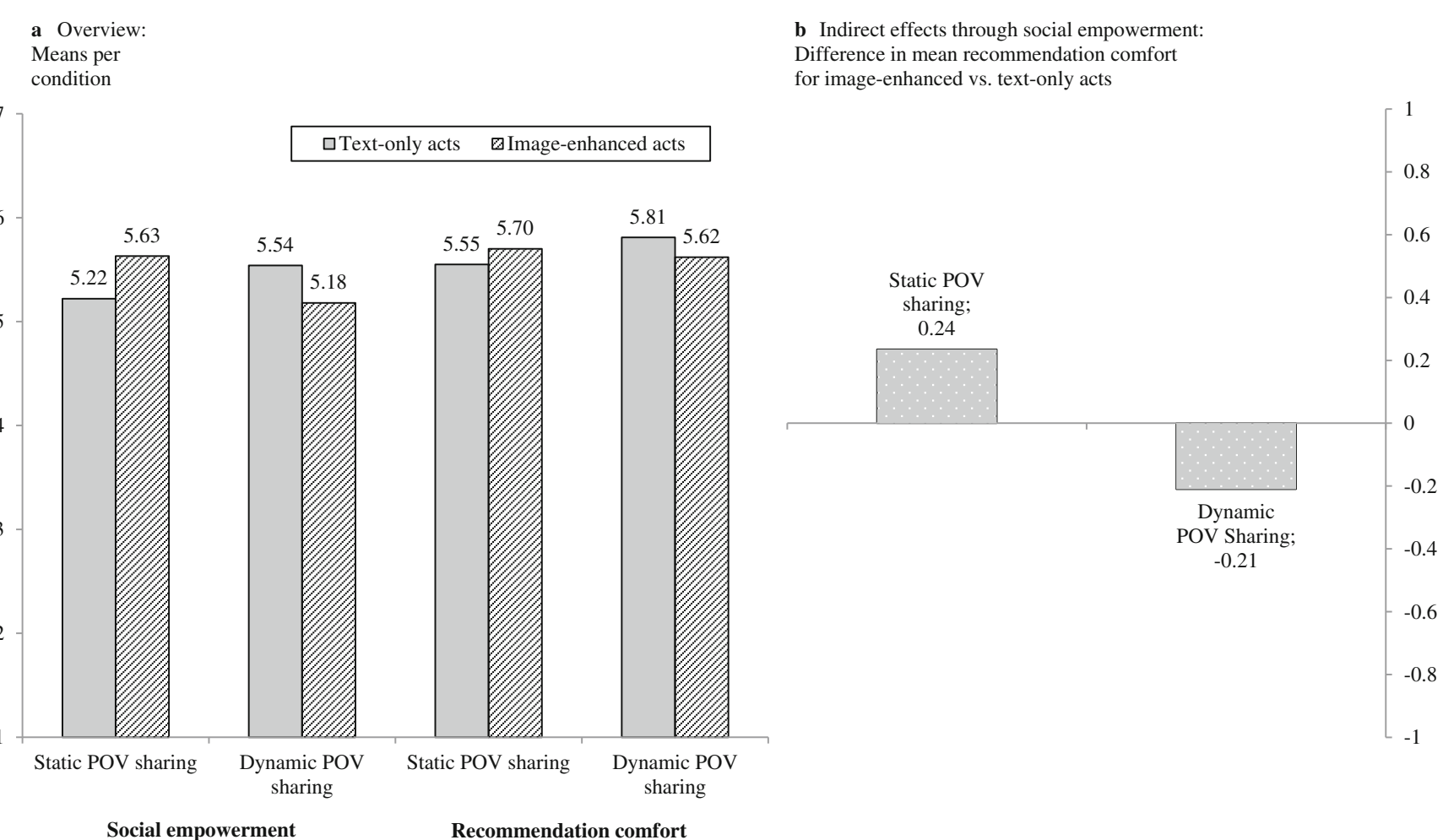

Fig. 4 Study 2: (Indirect) effects of image-enhanced or text-only acts with static or dynamic POV sharing on (through) social empowerment and (on) recommendation comfort

comfort. The $95 \%$ bias-corrected confidence intervals (CIs) for the coefficient excluded 0 ( $\beta=.24,95 \% \mathrm{CI}=.07$ to .47$)$. For participants who received a video, the direction of the indirect effect suggested greater social empowerment and resulting recommendation comfort from using a text-only act to convey their recommendation, but this effect did not reach statistical significance $(\beta=-.21,95 \% \mathrm{CI}=-.53$ to .03$)$.

\section{Discussion}

In support of $\mathrm{H} 2$, this study demonstrates that optimal configurations of social AR, in terms of POV sharing formats and communicative acts, enable a recommender to support a decision maker in their choice. This experience manifests as a sense of social empowerment, which allows the recommender to feel more comfortable with making a recommendation. We also find that social AR may enable the recommender to engage more in the choice process, but this engagement does not enhance recommendation comfort. Therefore, the benefits of social AR appear to stem from its ability to integrate a recommender into another customer's decision making process by allowing him or her to contribute in a convenient, meaningful way. In our next study, we identify an important boundary condition to these findings (H3).

\section{Study 3}

\section{Design and procedure}

We test $\mathrm{H} 3$, regarding the potential attenuation of the positive relationship between social empowerment and recommendation comfort, by the strength of a recommender's impression management concerns. The AR application and experimental procedure were the same as in Study 1. In exchange for course credit, 126 participants from a large public university completed the study in a lab setting, where they were randomly exposed to the manipulations in the same 2 (static vs. dynamic POV sharing $) \times 2$ (text-only vs. image-enhanced acts) between-subjects design. We excluded responses by participants who had technical difficulties (3), or did not understand the scenario and/or provide a recommendation (19), yielding a final sample of 104 participants ( 18 to 23 years; 44 women, 60 men).

\section{Measures}

The recommendation comfort $(\alpha=.80)$ and social empowerment $(\alpha=.86)$ measures were the same as in our previous studies. For the moderator, we asked participants to rate the strength of their impression management concerns on an adapted five-item scale ( $1=$ "strongly disagree" to 
$7=$ "strongly agree"; $\alpha=.77$; Dillard et al. 1989) that included items such as "I was concerned with making a good impression through my recommendation." Previous research identifies customer preferences for verbal versus visual information processing as a boundary condition in AR experiences (Hilken et al. 2017). We therefore controlled for participants' preferred style-of-processing, by asking them to complete a ten-item measure ( $\alpha=.75$; Ramsey and Deeter-Schmelz 2008 ) on a four-point scale ("always true" to "always false"), where high (low) scores imply a visual (verbal) disposition. To ensure that feelings of comfort did not reflect the nature of the relationship with the friend they were advising, we controlled for interpersonal closeness with the "inclusion of other in the self" scale by Aron et al. (1992). We summarize the items in Appendix 2.

\section{Results}

Manipulation checks The manipulation checks were significant and in the anticipated direction for POV sharing $\left(\mathrm{M}_{\text {Photo }}=4.49, \mathrm{M}_{\text {Video }}=5.00, \mathrm{t}(102)=-2.36, p=.020\right)$ and communicative acts $\left(\mathrm{M}_{\text {Text }}=5.34, \mathrm{M}_{\text {Image }}=6.17, \mathrm{t}(102)=\right.$ $-4.28, p<.001)$. They also exhibited good internal consistency $\left(\alpha_{\mathrm{POV}}=.83 ; \alpha_{\text {Communicative }}=.82\right)$.

Moderated mediation analysis Table 2, Panel A shows the results of our analysis in the PROCESS macro (Hayes 2013, Model 22). Controlling for style-of-processing and interpersonal closeness in all analyses, we found a significant antagonistic (negative) effect of the POV sharing $\times$ communicative acts interaction term on social empowerment $(\beta=-.70$, $p=.022)$. In support of $\mathrm{H} 3$, we also identified a negative social empowerment $\times$ impression management concerns interaction effect on recommendation comfort $(\beta=-.14, p=.050)$. Using a bootstrapping procedure with 5000 samples and biascorrected confidence intervals (CI), we analyzed the conditional indirect effects. Consistent with our previous findings, we found a significant indirect effect of image-enhanced acts through social empowerment on recommendation comfort, but only for participants who received a photo (static POV sharing; Table 2, Panel B). We analyzed this conditional indirect effect at the mean value (4.06), and one standard deviation above (5.23) and below (2.88) the mean value of the recommender's impression management concerns (Table 2, Panel B). In line with $\mathrm{H} 3$, the indirect effect grew weaker from low $(\beta=.20,95 \% \mathrm{CI}=.00$ to .50$)$ to medium $(\beta=.14,95 \%$ $\mathrm{CI}=.01$ to .37$)$ levels and did not reach statistical significance at high levels $(\beta=.08,95 \% \mathrm{CI}=-.01$ to .32$)$.

\section{Discussion}

The results of Study 3 reconfirm that when a recommender can only take the decision maker's POV in the decision context statically (i.e., receiving a photo rather than a video), conveying a recommendation through an image-enhanced act provides a sense of making a positive difference, or social empowerment, that results in recommendation comfort. In support of $\mathrm{H} 3$, recommenders who are very concerned about the impression they make on others derive less comfort from experiencing social empowerment. That is, because they are concerned about avoiding bad impressions, these customers likely find the feeling that their recommendation may have larger impact on another customer's decision making less comforting.

\section{Study 4}

\section{Design and procedure}

We sought evidence of the effects of social AR on decision makers. Specifically, we investigated how different communicative acts (text-only vs. image-enhanced) influence a decision maker's choice (H4) and if this effect is moderated by a recommender's persuasion goal (H5). We employed a dyadic experimental design in a lab setting, in which we randomly paired participants and assigned them to the role of either recommender or decision maker. The decision making scenario matched that from our previous studies. The decision makers were responsible for choosing a new wall color for a university education room. They used Akzo Nobel's AR application on a tablet PC to try out different wall colors; they also shared a photo of the room with another participant, who used the same application on another tablet PC to provide a choice recommendation. Participants then completed an online survey.

The AR visualizer application provided a photo of the room to all participants, so they experienced static POV sharing. The communicative acts manipulation was the same as in our previous studies. That is, depending on their role in the dyad, participants communicated (received) a recommendation, in the form of (1) a written message or (2) a written message plus a photo enhanced with AR content. This study thus had a one-factor (text-only vs. image-enhanced acts) between-subjects design. We recruited 332 participants (18 to 27 years; 172 women, 160 men) from a large public university in exchange for course credit, to form 166 dyads. We excluded any dyads in which participants reported technical difficulties (6), did not provide (receive) a recommendation (26), or did not make a final color choice (3), resulting in a final sample of 131 dyads.

\section{Measures}

To measure decision maker social empowerment, we used the scale from our previous studies but reversed the reference 
Table 2 Study 3: results

Panel A: Regression results

Independent variables

Constant

POV sharing

Communicative acts

POV sharing $\times$ communicative acts

Social empowerment

Impression management concerns

Social empowerment $\times$ impression management concerns

Style-of-processing

Interpersonal closeness

$\mathrm{R}^{2}$

MSE

$\mathrm{F}$

df

Panel B: Moderated mediation analysis results

Recommendation comfort

Conditional indirect effect of image-enhanced (vs. text-only) acts for Impression management concerns

Static POV sharing

2.88

4.06

5.23

Dynamic POV sharing

2.88

4.06

5.23
Social empowerment

$3.73 * *$

(.66)

$.53 *$

(.22)

$.36 \dagger$

(.19)

$-.70 *$

(.30)

$-$

(1)

$-$$$
-
$$$$
.33
$$

.06

(.06)

.10

.55

$2.18 \dagger$

5,98
Recommendation comfort

.95

(1.70)

$-.09$

(.22)

$-.09$

(.19)

$-.07$

(.30)

$.94 * *$

$-.14 *$

.04

(.06)

.21

.48

$3.07 * *$

8,95

\begin{tabular}{llll} 
Boot indirect effect & Boot SE & $95 \%$ LCI & $95 \%$ UCI \\
.20 & .12 & .00 & .50 \\
.14 & .09 & .01 & .37 \\
.08 & .08 & -.01 & .32 \\
-.18 & .13 & -.49 & .03 \\
-.13 & .09 & -.34 & .01 \\
-.07 & .07 & -.27 & .01 \\
\hline
\end{tabular}

The numbers in parentheses are standard errors. This table provides unstandardized coefficients. SE = standard error; $\mathrm{LCI}=$ lower confidence interval, $\mathrm{UCI}=$ upper confidence interval

Significance based on two-tailed tests: $* * p<.01, * p<.05, \dagger p<.1$

point (e.g., "I feel that my friend's recommendation made a positive difference in my decision making"; $\alpha=.94$ ). To assess whether the decision maker's choice was influenced by the recommendation, we coded a choice variable, equal to 1 if the decision maker's choice of color was in the same color group as the recommended color, and 0 otherwise. ${ }^{5}$ We controlled for the extent to which the recommended color fit the decision maker's existing color preferences with an adapted three-item measure ( $\alpha=.76$; Zhang et al. 2011). Strength of

\footnotetext{
${ }_{5}^{5}$ To ensure valid coding, we relied on Akzo Nobel's color chart in the Visualizer application, which consists of 12 overarching color groups that mimic the visible color display spectrum.
}

the recommender's persuasion goal was measured on a fiveitem scale $(\alpha=$.65) from Dillard et al. (1989), which we modified to fit the study context (e.g., "I was very concerned about getting my friend to choose the color I recommended"). All scales, as listed in Appendix 2, ranged from 1= "strongly disagree" to $7=$ "strongly agree."

\section{Results}

Manipulation checks We assessed our communicative acts manipulation for recommenders with the four items from our previous studies $(\alpha=.82)$. The manipulation worked as 
intended $\left(\mathrm{M}_{\text {Text }}=4.68, \mathrm{M}_{\text {Image }}=5.76, \mathrm{t}(119)=-5.40\right.$, $p<.001)$. For decision makers, we adapted the items by shifting the reference point (e.g., "Using the app allowed me to see how the color that my friend recommended fits the room"). The resulting measure exhibited good internal consistency $(\alpha=.88)$, and the manipulation was successful $\left(\mathrm{M}_{\text {Text }}=\right.$ $\left.4.75, \mathrm{M}_{\text {Image }}=5.99, \mathrm{t}(101)=-5.98, p<.001\right)$.

Moderated mediation analysis Table 3 shows the results of our analysis in the PROCESS macro (Hayes 2013, Model 14). Controlling for how well the recommendation fit the decision maker's color preferences, we found a significant positive effect of image-enhanced acts on social empowerment $(\beta=.51$, $p=.017$ ). Supporting $\mathrm{H} 4$ and $\mathrm{H} 5$, a binary logistic regression with the decision maker's choice as the dependent variable yielded a significant positive effect of social empowerment $(\beta=2.10, \operatorname{Ex}(\beta)=8.19, p=.002)$ and a significant negative social empowerment $\times$ recommender's persuasion goal interaction effect $(\beta=-.50, \operatorname{Ex}(\beta)=.61, p=.009)$. Bootstrapping with 5000 samples for conditional indirect effects revealed that participants who received a recommendation through an image-enhanced act felt socially empowered and were more likely to follow the recommendation and choose from the recommended color group. However, this effect grew weaker from low $(2.06, \beta=.54,95 \% \mathrm{CI}=.06$ to 1.52$)$ to medium (2.98, $\beta=.31,95 \% \mathrm{CI}=.02$ to .85$)$ levels, and was no longer statistically significant at high levels $(3.89, \beta=.07,95 \% \mathrm{CI}=-.23$ to $.56)$ of the recommender's persuasion goal.

\section{Discussion}

The results of this study extend our previous findings to decision makers' consideration and actual choice. When decision makers use social AR to share their POV through a static photo, and in turn receive a choice recommendation through an image-enhanced act, they sense that another person is making a positive difference in their decision making (i.e., social empowerment). This increases their likelihood of relying on the recommendation in their choice of product. However, this effect is mitigated when the recommender has a strong persuasion goal, as this self-serving motive likely contradicts the decision maker's pro-social perception of social empowerment and thus leads to a dismissal of the recommendation.

\section{Study 5}

\section{Design and procedure}

We investigated stage 4 of the shared decision making process with social AR, by testing whether a sense of social empowerment amongst recommenders stimulates their desire for a product (H6a) and increases intentions to use (H6b) and spread positive word-of-mouth about (H6c) the social AR application. We employed a survey method with the same experimental procedure as in Studies 1-3. Participants used the desktop version of Akzo Nobel's Visualizer to recommend

Table 3 Study 4: regression and binary logistic regression results

\begin{tabular}{|c|c|c|c|}
\hline \multirow[t]{2}{*}{ Independent variables } & \multirow[t]{2}{*}{ Social empowerment } & \multicolumn{2}{|l|}{ Choice } \\
\hline & & $\mathrm{B}(\mathrm{SD})$ & Odds Ratio \\
\hline Constant & $\begin{array}{l}1.53 * * \\
(.32)\end{array}$ & $\begin{array}{l}-12.93 * * \\
(3.38)\end{array}$ & .00 \\
\hline Communicative acts & $\begin{array}{l}.51 * \\
(.21)\end{array}$ & $\begin{array}{l}.19 \\
(.51)\end{array}$ & 1.21 \\
\hline Decision maker social empowerment & - & $\begin{array}{l}2.10^{* *} \\
(.67)\end{array}$ & 8.19 \\
\hline Recommender persuasion goal & - & $\begin{array}{l}2.11 * \\
(.84)\end{array}$ & 8.21 \\
\hline Decision maker social empowerment $\times$ recommender persuasion goal & - & $\begin{array}{l}-.50 \text { ** } \\
(.19)\end{array}$ & .61 \\
\hline Recommendation fit with decision maker preferences & $\begin{array}{l}.52 * * \\
(.07)\end{array}$ & $\begin{array}{l}.58 * * \\
(.22)\end{array}$ & 1.79 \\
\hline $\mathrm{R}^{2} /$ Cox \& Snell $\mathrm{R}^{2}$ & .30 & .24 & \\
\hline MSE / Nagelkerke $\mathrm{R}^{2}$ & 1.43 & .37 & \\
\hline $\mathrm{F} / \mathrm{X}^{2}$ & $27.32 * *$ & $35.37 * *$ & \\
\hline $\mathrm{df}$ & 2,128 & 5,125 & \\
\hline
\end{tabular}

The numbers in parentheses are standard errors. This table provides unstandardized coefficients

Significance based on two-tailed tests: $* * p<.01, * p<.05, \dagger p<.1$ 
a color choice to a friend. Focusing on the marketing-relevant consequences of using social AR to provide purchase advice, we followed the approach from Study 4 where participants received a photo of the decision context (static POV sharing). They could project colors virtually onto the walls and convey their recommendation by sending a photo of the color in the room with a written message (image-enhanced act). We recruited 360 participants through Amazon MTurk in exchange for a small payment. We excluded participants who used an incompatible operating system (32), reported technical difficulties (7), did not use the app (13), did not understand the scenario and/or provide a recommendation (37). The final sample consisted of 271 participants (19 to 73 years; 129 women, 142 men).

\section{Measures}

We used the social empowerment measure $(\alpha=.94)$ from our previous studies. Participants rated their intention to use the application in the future with an adapted three-item measure (e.g., "The next time I need to choose a new wall color, I will use the app"; $\alpha=.94$; Hanson and Yuan 2018) and their WOM intentions with a three-item measure $(\alpha=.95$; Zeithaml et al. 1996). We also asked participants whether they were currently considering a new wall color for their home. 217 participants for whom this did not apply, rated the extent to which providing a recommendation through social AR stimulated their desire for the product on an adapted threeitem product-usage thoughts measure (e.g., "While using the app, how much did you think about the possibility of changing your current wall color or decorations in your home?"; $\alpha=.95$; Bruner 2009; Escalas and Luce 2004). We list all items in Appendix 2.

\section{Results}

We individually regressed desire for the product $\left(\mathrm{R}^{2}=.02, \mathrm{~F}(1\right.$, $215)=3.96, p=.048)$, app usage intentions $\left(\mathrm{R}^{2}=.07, \mathrm{~F}(1\right.$, $269)=18.64, p<.001)$, and WOM intentions $\left(\mathrm{R}^{2}=.14, \mathrm{~F}(1\right.$, $269)=43.39, p<.001)$ on social empowerment. In support of H6a-c, we found significant positive effects of social empowerment on desire for the product $(\beta=.27, t(215)=1.99$, $p=.048)$, and app usage $(\beta=.39, \mathrm{t}(269)=4.32, p<.001)$ and WOM $(\beta=.56, \mathrm{t}(269)=6.59, p<.001)$ intentions.

\section{General discussion}

With this research, we provide a more in-depth understanding of how social AR supports shared decision making amongst customers and leads to marketing-relevant outcomes for firms.
We take a dyadic perspective and draw on socially situated cognition theory to identify optimal configurations of social AR's key features (POV sharing and communicative acts) depending on the customer role at the different stages of shared decision making.

For recommenders, we demonstrate that image-enhanced acts may compensate for static POV sharing and let them feel comfortable with providing a visually enhanced product recommendation. We also find initial evidence that dynamic POV sharing formats may be complementary to providing text-only recommendations. These effects stem from a feeling of social empowerment, such that the recommender experiences comfort from the sense that he or she is making a positive difference in another customer's decision making. The effect of social empowerment on decision comfort is weaker for recommenders with strong impression management concerns, because they want to avoid negative self-presentation. We also provide initial evidence for the marketing-relevant outcomes of letting recommenders use social AR to contribute to other's purchase decisions, in the form of stimulating desire for the product and triggering positive behavioral intentions towards the social AR application.

For decision makers, we find that image-enhanced (vs. text-only) acts enable them to feel socially empowered through another customer, which increases the likelihood of incorporating a recommendation into their choice of product. However, this effect is attenuated by the extent to which the recommender is motivated by a persuasion goal, which is at odds with the decision maker's pro-social perception of social empowerment.

\section{Implications for theory}

We extend current marketing literature on AR-enhanced customer experiences in three related ways. First, we advance socially situated cognition as a theoretical basis for understanding social AR as an enabler of shared decision making, which establishes a conceptual foundation for emerging research on customer-to-customer interactions through AR (Hilken et al. 2017; Scholz and Smith 2016). In doing so, we are the first to define social AR, conceptualize its key features, and empirically model their influence on customer recommendations and choices. Framing decision making as a multi-staged, social process and taking a dyadic perspective, we demonstrate how recommenders and decision makers may use social AR to lean on each other's support in online purchase decisions. We also help address a current research gap regarding the optimal configuration of AR applications in terms of formats and communication modes (Javornik 2016). Thus, we advance research on the combination of text and image acts in social media (Villarroel Ordenes et al. 2018) 
and help explain some controversy in previous findings regarding customers' preferences for photo or video formats (de Vries et al. 2012). Our findings reveal that, on the one hand, social AR may help satisfy customers' needs for better visualization in joint product evaluations (Füller et al. 2009) and thus compensate for poor POV sharing, by enabling recommenders to offer advice in a visually enhanced way. Then decision makers can build on those recommendations more readily. On the other hand, facilitating dynamic POV sharing may complement a recommender's ability to provide textonly recommendations, resulting in greater recommendation comfort. Consistent with literature emphasizing the importance of enabling customers to share a common perspective during online shopping (Zhu et al. 2010), and previous research on static versus dynamic AR formats (He et al. 2018), we find that when a recommender can take the decision maker's POV dynamically, he or she appears to feel comfortable with providing a text-only recommendation.

Second, we contribute to a growing research stream on social forms of customer empowerment (Hanson and Yuan 2018). Previous literature emphasizes a sense of selfempowerment when customers individually use AR for their online purchases (e.g., to better assess product features; Poushneh 2018). We extend this finding to the social context, by establishing social empowerment as a mediating mechanism by which social AR facilitates shared decision making. Our empirical evidence affirms propositions that suggest that successful deployment of social AR relies on enhancing sociability among customers (Scholz and Smith 2016). We demonstrate the dual nature of social empowerment based on the customer's role in decision making. Recommenders derive a sense of comfort when they feel enabled to make a positive difference for another customer, through using social AR. For decision makers, soliciting support from other customers through social AR may provide a new source of empowerment in online purchase decisions, in addition to online communities (Adjei et al. 2010), reviews or ratings (Moe and Trusov 2011), and social media platforms (Wang et al. 2012). This mediation is robust, in that we rule out personal choice engagement as an alternative mechanism. Although social AR applications likely promote personal engagement, customer decision making improves due mainly to an enhanced ability to share what they perceive to be socially empowering choice recommendations.

Third, by investigating recommenders' distinct motivations for providing a recommendation, we address a current paucity of knowledge regarding customer-related boundary conditions to social AR use (Hilken et al. 2018). Specifically, we help explain why AR-enabled social empowerment (1) is less comforting for some recommenders than others and (2) influences decision makers' choices more in some customer dyads than in others. For many recommenders, impression management is a relevant concern, particularly online (Oh and LaRose 2016), but it may conflict with a goal of providing social support (Berger 2014). Consistently, our results reveal that a recommender who is motivated to prevent a negative self-presentation derives less recommendation comfort from his or her enhanced ability to positively impact another customer's decision through social AR. We also show that the more the recommender is motivated to pursue a persuasion goal, the less likely the decision maker is to incorporate the recommendation in their choice. Decision makers likely find persuasive attempts an infringement of the pro-social nature of social empowerment; as previous research demonstrates, customers are less likely to share highly directive communication from firms (Villarroel Ordenes et al. 2018). Our research extends these findings to the context of customer-to-customer communication about purchase decisions.

\section{Implications for managers}

To increase purchase rates, many firms seek to encourage customer-to-customer interactions online (Adjei et al. 2010), as this enables customers to exchange advice with friends and family (Zhu et al. 2010). Social AR promises to facilitate these interactions by allowing customers to share and virtually enhance a common view of the physical environment. Yet, managers need guidance to exploit AR's full potential (DigitalBridge 2017). For firms seeking to upgrade the AR experiences they offer, we provide several relevant insights, detailing effective configurations and deployments of social AR.

First, firms can use emerging social AR to strengthen the benefits of online shopping for the customer as a means of improving conversion rates and countering webrooming behavior (i.e., where customers use the online channel to obtain product and price information but ultimately purchase offline). Current AR apps for online shopping have limited customerto-customer interactions to exchanging screenshots of AR content through third-party social media, which does not satisfy customers' expectations of a seamless omnichannel experience (Brynjolfsson et al. 2013; Hilken et al. 2018). When customers perceive channel limitations (e.g., a lack of sociability in online shopping) and feel the need to switch channels (e.g., to examine products in store with friends and family), this may result in churn. We demonstrate that optimal configurations of social AR can facilitate a seamless online shopping experience, where customers can not only "try out" products without leaving the comfort of their homes but also exchange advice with friends and family without switching between apps or channels. This results in relevant benefits for customers in shared decision making. That is, recommenders feel 
more comfortable with giving advice, and in turn, decision makers feel empowered in their purchase decisions, making them more likely to follow others' recommendations, which likely preempts channel switching and webrooming, whilst increasing online sales for firms.

Second, in deploying emerging social AR technologies, firms can exploit the growing trend of communication using predominantly images (e.g., Snaps, Instagram stories) rather than text (Bilton 2006). Our findings suggest that when optimally configured, firms may reap benefits from letting customers use both static and dynamic visual sharing formats. Using static photos in combination with image-enhanced acts as the exchange format for social AR is an easy-to-deploy tool to enhance customer-to-customer interactions, as firms can leverage customers' existing familiarity with sharing and virtually altering photos. Videos likely are the future of social media (American Marketing Association 2016), and as we show, video-based AR allows customers to share their POV dynamically, which may complement text-only communications about online purchases. Thus, when deploying social AR in video formats, complementing this with text messages or chat features could be a fruitful combination. Finally, as customers grow increasingly comfortable with virtually enhancing videos, firms should give them free rein to choose their preferred combination of POV sharing formats (photo or video) and communication modes (text and/or image) when they create and communicate through AR content.

Third, firms should promote social AR applications by emphasizing their potential for social empowerment. Customers find the realism of AR content important (Hilken et al. 2017), but we demonstrate the ability of social AR to provide and receive support for shared purchase decisions. Thus, in addition to promoting AR as a tool for "visualizing" (Akzo Nobel), "placing" (IKEA), or "trying before buying" (L'Oreal), firms should also communicate AR's social value proposition. We recommend revising AR-related communication strategies so as to present AR as a tool for sharing, supporting, and connecting with others. In this respect, firms could especially focus on inviting customers to use social AR for providing recommendations, as this leads to marketingrelevant spillover effects. A sense of social empowerment amongst recommenders stimulates their own desire for products, and thus may provide firms with a new way of generating online sales. Social empowerment also increases recommenders' positive word-of-mouth and usage intentions, and thus might help firms to address currently low technology adoption rates for AR.

Fourth, in deploying social AR, firms should, as far as possible, account for customers' differing motivations when providing purchase advice. Strong impression management concerns may inhibit recommendation comfort, so firms should build features into social AR applications that alleviate concerns about negative self-presentation. For example, displaying frequently recommended choices or making virtual advisors accessible to recommenders may help allay anxiety about giving inappropriate advice. The ability to recall or update a recommendation might also reduce the perceived risk of giving advice. Because impression management concerns are amplified when communication is highly visible (Berger 2014), direct customer-to-customer communication may be preferable to publicly shared AR-enabled recommendations. That is, firms are well advised to let customers choose between public posting and private messaging features in their social AR applications.

Fifth, in line with previous research (Fransen et al. 2015), we show that decision makers may dismiss overly persuasive communication. Firms should thus facilitate socially empowering interactions through social AR. For example, priming recommenders with pro-social cues (e.g., asking them to spend time to help a friend; Mogilner 2010) may place recommenders in a less persuasion-oriented mindset. Recommendation text templates that establish an expressive (vs. directive) form or that require recommenders to provide a balanced recommendation (e.g., include pros and cons of a choice option) may also counteract a persuasion goal. To support decision makers, firms could enable them to communicate preferences (e.g., restricting choice options to a certain color palette), which may prompt recommenders to provide more tailored, supportive advice (Kirmani and Campbell 2004).

\section{Limitations and further research}

Our results generally support the hypothesized optimal configurations of POV sharing formats and communicative acts. ${ }^{6}$ Yet for dynamic (video) POV sharing, we do not find sufficient statistical evidence to support our prediction that recommenders feel more comfortable communicating through textonly rather than image-enhanced acts. More research might address this relationship to identify specific contexts in which

\footnotetext{
${ }^{6}$ The interaction term has a significant direct effect in Study 1 and indirect effects through social empowerment on recommendation comfort in Studies 2 and 3. Although the mediator regression model in the latter studies yielded lower $\mathrm{R}^{2}$ values, we find support for the hypothesized effects in the bootstrapped, bias-corrected confidence intervals associated with the betas for the conditional indirect effects in the dependent variable model (Hayes 2013). Acknowledging the inherent complexity of human decision making, future research might study factors that shape social empowerment and recommendation comfort in addition to the configurations of social AR, but as we test our hypothesized causal relationships in an experimental design (including randomization and relevant control variables), we are confident that the effect is reasonably established through our studies.
} 
recommenders find written communication about AR content superior to sharing visualizations. For decision makers, we focus on studying how recommendations conveyed through different communicative acts shape social empowerment and actual choice, but further research might address the possibility of an extended influence of POV sharing formats throughout the shared decision making process. The format in which the decision maker initially shares their POV may set the tone for the overall process and may indirectly amplify the observed effects in stages 3 and 4. Relatedly, symmetry effects in communication may arise over time and through multiple feedback loops, such that recommenders and decision makers might form shared preferences regarding not only the sharing formats and communication modes, but also choice outcomes. Thus, longitudinal research designs might yield additional insights into optimal configurations of social AR for shared decision making.

In our empirical studies, we model a dyadic decision making process where the decision maker and recommender are "purchase pals" (i.e., friends or family), and there is a clear distinction between the two roles. This design reflects common online customer interactions and we control for differing levels of interpersonal closeness, but continued research might address social AR-enabled decision making in large groups or that involves shared responsibility for an outcome. Furthermore, as previous research has identified different types of dyadic customer relationships (Keeling et al. 2013), it would be interesting to study how different recommenders (e.g., casual acquaintances, firm employees, or virtual assistants) might influence our observed effects. Particularly the pro-social focus of an exchange might shift depending on the type of relationship, resulting in potential non-linear effects, for example, of the recommender's persuasion goal on the decision maker's choices.

We study how individual differences in recommenders' communication motives impede shared decision making. Our focus on concerns about avoiding negative impressions is consistent with extant literature (Berger 2014; Oh and LaRose 2016), but a parallel research stream emphasizes that impression management can also be motivated by a desire for positive self-presentation and result in increased self-esteem (Pounders et al. 2016). This perspective warrants further study, as it points to potential tension in communication motives that might require balancing behaviors by recommenders (e.g., through "humblebragging"; Sezer et al. 2018). Research into positive impression management also might inform managers about additional functionalities such as (e.g., gamified) reward or recognition mechanisms (e.g., on social media) that may strengthen the recommender comfort. With regard to a recommender's persuasion goal, future research could explore the enactment of this motive more explicitly. For instance, a content analysis of the text messages and images exchanged by the participants in our studies was beyond the scope of our research. Yet, marketing researchers are developing increasingly sophisticated text- and image-mining methods (Villaroel Ordenes et al. 2018). An extension of our research would be to analyze how distinct communication motives manifest in the content or style of the communicative acts conveyed through social AR. Relatedly, it would be useful to establish how firms might deploy social AR to facilitate the exchange of specific communicative content, such as objective information (This product fits well with your décor), emotions (This product creates a calm, soothing atmosphere), or calls to action (Choose this product for your home!) via text-only or image-enhanced acts.

On a related note, global customer connectivity may spur social AR use across cultural boundaries, so there is a need for studying cultural differences in its adoption and use. For instance, a recommender's focus on preventing negative impressions (e.g., "losing face") versus promoting the self may be driven, in part, by cultural orientation towards individualism or collectivism. Research also reveals that customers in collectivistic cultures seek peer support through social media (Kim et al. 2011) and thus might be more comfortable with exchanging advice through social AR, whereas more individualistic customers appear to prefer AR content that offers objective product information (Feng and Mueller 2018).

For firms, we offer initial evidence of marketingrelevant spillover effects from deploying social AR, in the form of recommenders' increased desire for products and positive behavioral intentions. Yet research might conduct further (field) studies to extend the analysis of these attitudinal measures to actual purchase behavior(s). Studying customers who complete a shared purchase journey (e.g., a couple redecorating their home, a friend advising them on the décor) might not only help to establish conversion and adoption rates, but also provide new insights into how firms might use social AR for social cross-selling. A specific focus of such longitudinal research could be the potential time to conversion and/or attrition rates between stimulating spillover effects and actual purchase (or not) by recommenders and possible conversion mechanisms that could be devised and employed.

Finally, we study a current application of social AR that allows consumers to share decision contexts using photo and video formats. The next generation of social AR applications (e.g., Microsoft Hololens Skype) promises to allow customers to share and jointly enhance live views of their physical environment. The effects of POV sharing and communicative acts when such AR enables synchronous (vs. asynchronous) enhancement of a decision context warrant further investigation. 


\section{Appendix 1}

Stage 1:

Requisition

Decision maker

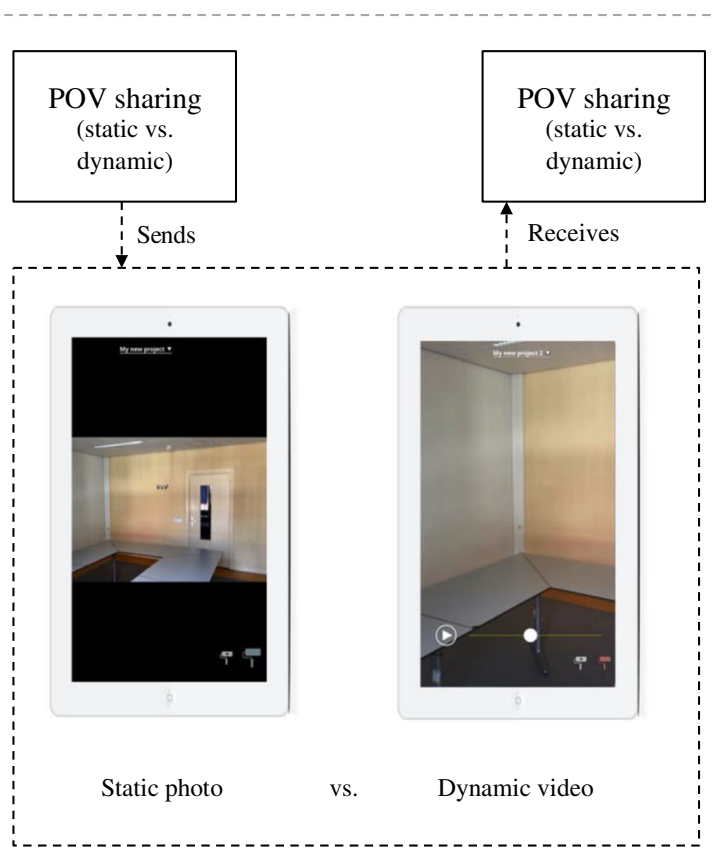

Stage 2:

Recommendation formulation and conveyance

Recommender
Stage 3:

Consideration and choice

Decision maker

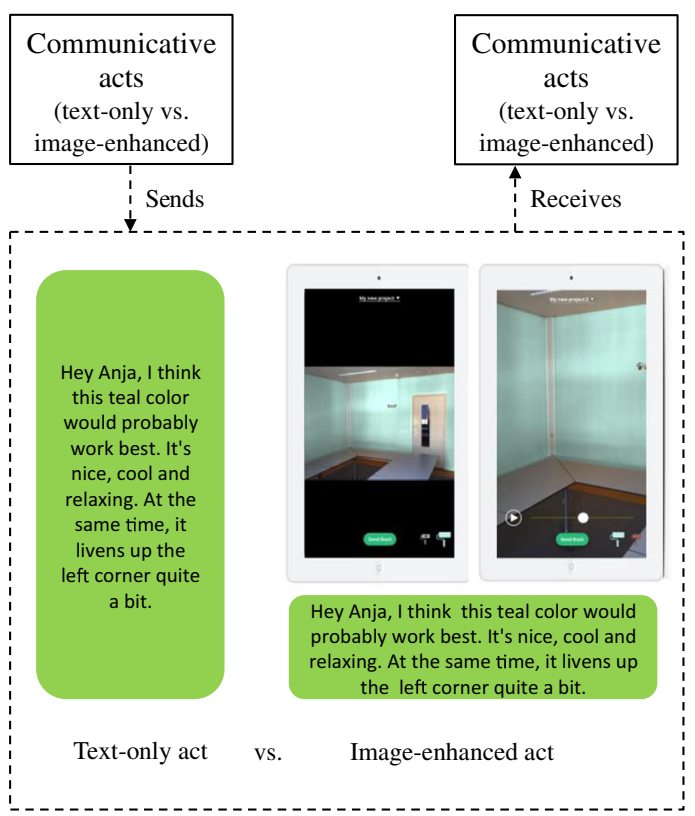

Fig. 5 Overview of experimental procedure, stimulus materials, and manipulations

\section{Appendix 2}

Table 4 Overview of constructs and measurement items

\section{Construct}

Communicative acts (recommender)

Using the app allowed me to show my friend how my recommended color fits the room.

Using the app allowed me to make my color recommendation visible to my friend.

Using the app allowed me to showcase my color recommendation to my friend.

Using the app allowed me to share my color recommendation with my friend.

POV sharing (recommender)

Using the app allowed me to move through the room as my friend would.

Using the app allowed me to copy my friend's movements and actions.

Using the app allowed me to take my friend's perspective in the decision at hand.

Using the app allowed me to understand the decision my friend is facing.

Using the app allowed me to put myself in my friend's shoes.
Items

Communicative acts (decision maker)

Using the app allowed me to see how the color that my friend recommended fits the room.

Using the app allowed me to get a visible color recommendation from my friend.

Using the app allowed me to receive a showcase of the color that my friend recommended.

Using the app allowed me to obtain a color recommendation my friend. 
Table 4 (continued)

Recommendation comfort (recommender) adapted from Parker et al. (2016)

I am comfortable with recommending my friend to choose this color.

I feel good about recommending my friend to choose this color.

I am experiencing negative emotions about recommending my friend to choose this color. (R)

Whether or not it is "the best choice," I am okay with recommending my friend to choose this color.

Although I don't know if this color is the best, I feel perfectly comfortable with the choice I recommended to my friend.

Social empowerment (recommender) adapted from Hanson and Yuan (2018)

I feel that I'm making a positive difference in my friend's decision making.

I feel like I'm making a positive impact for my friend.

I feel like I'm making a meaningful difference for my friend.

I feel that my recommendation made a positive difference in my friend's decision making.

My recommendation improved my friend's decision making.

I had a positive impact on my friend.
Social empowerment (decision maker) adapted from Hanson and Yuan (2018)

I feel that my friend is making a positive difference in my decision making.

I feel like my friend is making a positive impact for me.

I feel like my friend is making a meaningful difference for me.

I feel that my friend's recommendation made a positive difference in my decision making.

My friend's recommendation improved my decision making.

My friend had a positive impact on me.

Impression management concerns (recommender) adapted from Dillard et al. (1989)

I was concerned with making a good impression through my recommendation.

I was careful to avoid recommending a color that might be viewed as tasteless.

I was very conscious of what colors would be appropriate and inappropriate to recommend.

I was concerned with putting myself in a "bad light" through my recommendation.

I didn't want to look stupid through my recommendation.

Persuasion goal (recommender) adapted from Dillard et al. (1989)

It was very important to me that my friend chooses the color I recommended.

I was very concerned about getting my friend to choose the color I recommended.

I didn't really care that much whether my friend considers my recommendation or not. (R)

I felt that the outcome of my friend's decision has important personal consequences for me.

Although I wanted my friend to choose the color I recommended, it really wasn't that important an issue. (R)

Desire for the product (recommender) adapted from Escalas and Luce (2004)

While using the app, did you think about how a new wall color would look in your own home?

While using the app, how much did you think about the possibility of changing your current wall color in your home?

While using the app, how much did you think about choosing a new wall color for your home?

Usage intentions (recommender) adapted from Hanson and Yuan (2018)

The next time I need to choose a new wall color, I will use the app.

If I had needed to choose a new wall color during the past month, I would have used the app.

Within the next month, if I needed to choose a new wall color, I would use the app.

WOM intentions (recommender) Zeithaml et al. (1996)

Please indicate how likely you are to:

Say positive things about the app to other people.

Recommend the app to someone who seeks your advice.

Encourage friends and relatives to use the app.

Choice engagement (recommender) Mathmann et al. (2017)

Please indicate how well the words beside the checkboxes describe the process you just went through (i.e., finding a color you would recommend your friend to choose). The process was...

unimportant - important

of no concern - of concern to me

irrelevant - relevant

meaningless - meaningful to me

not beneficial - beneficial

doesn't matter - matters to me

boring - interesting

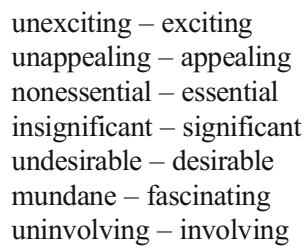

Style-of-processing (recommender) Ramsey and Deeter-Schmelz (2008)

There are some special times in my life that I like to relive by mentally "picturing" just how everything looked.

I like to daydream.

I find it helps to think in terms of mental pictures when doing many things.

When I have forgotten something I frequently try to form a mental "picture" to remember it. 
Table 4 (continued)

My thinking often consists of mental "pictures" or images.

I enjoy work that requires the use of words. (R)

I enjoy learning new words. (R)

I like to think of synonyms for words. (R)

I like learning new words. (R)

I spend very little time attempting to increase my vocabulary. (R)

Inclusion of the other in the self (recommender) Aron et al. (1992)

Please select the picture below which best describes your relationship with your friend.
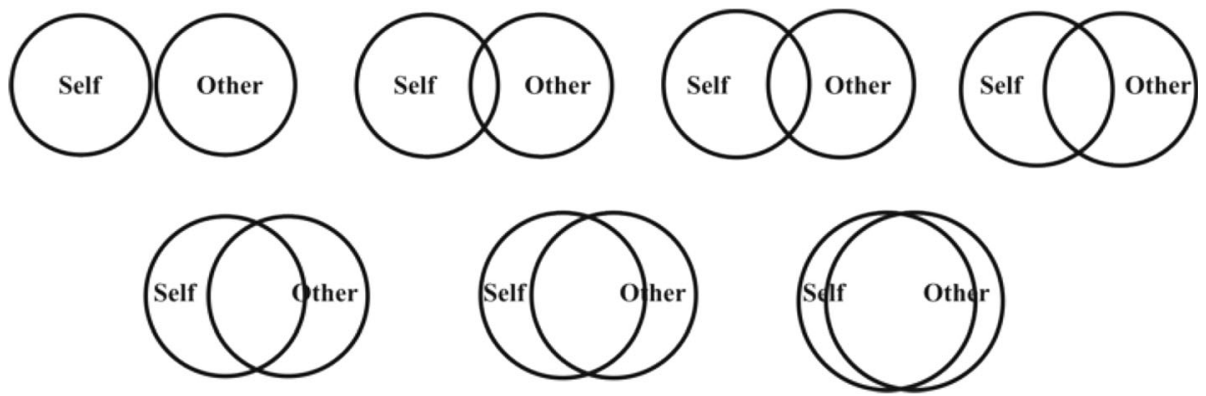

Recommendation fit with preferences (decision maker) adapted from Zhang et al. (2011)

My friend's recommendation matched my personal color preferences very well.

My friend's recommendation fit my taste in color very well.

My friend's color recommendation was interesting to me.

$(\mathrm{R})=$ Reverse-coded item

Open Access This article is distributed under the terms of the Creative Commons Attribution 4.0 International License (http:// creativecommons.org/licenses/by/ 4.0/), which permits unrestricted use, distribution, and reproduction in any medium, provided you give appropriate credit to the original author(s) and the source, provide a link to the Creative Commons license, and indicate if changes were made.

\section{References}

Adjei, M. T., Noble, S. M., \& Noble, C. H. (2010). The influence of C2C communications in online brand communities on customer purchase behavior. Journal of the Academy of Marketing Science, 38(5), 634 653.

American Marketing Association (2016). Social media video content is about to explode. https://www.ama.org/publications/Marketing News/Pages/video-content-about-to-explode.aspx. Accessed 20 April 2018.

Aron, A., Aron, E. N., \& Smollan, D. (1992). Inclusion of other in the self scale and the structure of interpersonal closeness. Journal of Personality and Social Psychology, 63(4), 596-612.

Artillry - Artillery Intelligence (2019). AR commerce: monetization comes into view. https://artillry.co/artillry-intelligence/arcommerce-monetization-comes-into-view/. Accessed 20 Feb 2019.

Bartling, B., \& Fischbacher, U. (2012). Shifting the blame: On delegation and responsibility. The Review of Economic Studies, 79(1), 67-87.
Batra, R., \& Keller, K. L. (2016). Integrating marketing communications: New findings, new lessons, and new ideas. Journal of Marketing, $80(6), 122-145$.

Berger, J. (2014). Word of mouth and interpersonal communication: A review and directions for future research. Journal of Consumer Psychology, 24(4), 586-607.

Bilton, N. (2006). Disruptions: Social media images form a new language online. The New York Times: Bits. https://bits.blogs.nytimes.com/ 2013/06/30/disruptions-social-media-images-form-a-newlanguage-online/. Accessed 3 Nov 2017.

Blazevic, V., Hammedi, W., Garnefeld, I., Rust, R. T., Keiningham, T., Andreassen, T. W., Donthu, N., \& Carl, W. (2013). Beyond traditional word-of-mouth: An expanded model of customer-driven influence. Journal of Service Management, 24(3), 294-313.

Broniarczyk, S. M., \& Griffin, J. G. (2014). Decision difficulty in the age of consumer empowerment. Journal of Consumer Psychology, 24(4), 608-625.

Bruner, G. C. (2009). Marketing scales handbook: A compilation of multi-item measures for consumer behavior \& advertising research. Fort Worth: GCBII Publications.

Brynjolfsson, E., Hu, Y. J., \& Rahman, M. S. (2013). Competing in the age of omnichannel retailing. MIT Sloan Management Review, 54(4), 23-29.

Campbell, M. C., \& Kirmani, A. (2000). Consumers' use of persuasion knowledge: The effects of accessibility and cognitive capacity on perceptions of an influence agent. Journal of Consumer Research, 27(1), 69-83.

de Ruyter, K., Keeling, D. I., \& Ngo, L. V. (2018). When nothing is what it seems: A digital marketing research agenda. Australasian Marketing Journal, 26(3), 199-203.

de Vries, L., Gensler, S., \& Leeflang, P. S. (2012). Popularity of brand posts on brand fan pages: An investigation of the effects of social media marketing. Journal of Interactive Marketing, 26(2), 83-91. 
Deloitte (2016). The Deloitte Consumer Review-CX marks the spot: rethinking the customer experience to win. https://www2.deloitte. $\mathrm{com} /$ content/dam/Deloitte/uk/Documents/consumer-business/ deloitte-uk-consumer-review-customer-experience.pdf. Accessed 15 Jan 2019.

Diehl, K., Zauberman, G., \& Barasch, A. (2016). How taking photos increases enjoyment of experiences. Journal of Personality and Social Psychology, 111(2), 119-140.

DigitalBridge (2017). Augmented reality-changing the face of retail. http://digitalbridge.eu/download-our-new-report-augmentedreality-changing-the-face-of-retail/. Accessed 11 Nov 2017.

Dillard, J. P., Segrin, C., \& Harden, J. M. (1989). Primary and secondary goals in the production of interpersonal influence messages. Communications Monographs, 56(1), 19-38.

Escalas, J. E., \& Luce, M. F. (2004). Understanding the effects of processfocused versus outcome-focused thought in response to advertising. Journal of Consumer Research, 31(2), 274-285.

Feng, Y., \& Mueller, B. (2018). The state of augmented reality advertising around the globe: A multi-cultural content analysis. Journal of Promotion Management. Available online 22 March 2018, in press. https://doi.org/10.1080/10496491.2018.1448323.

Fransen, M. L., Verlegh, P. W., Kirmani, A., \& Smit, E. G. (2015). A typology of consumer strategies for resisting advertising, and a review of mechanisms for countering them. International Journal of Advertising, 34(1), 6-16.

Fuchs, C., \& Schreier, M. (2011). Customer empowerment in new product development. Journal of Product Innovation Management, 28(1), 17-32.

Fuchs, C., Prandelli, E., \& Schreier, M. (2010). The psychological effects of empowerment strategies on consumers' product demand. Journal of Marketing, 74(1), 65-79.

Füller, J., Mühlbacher, H., Matzler, K., \& Jawecki, G. (2009). Consumer empowerment through internet-based co-creation. Journal of Management Information Systems, 26(3), 71-102.

Gartner (2018). 3 reasons why VR and AR are slow to take off. https:// www.gartner.com/smarterwithgartner/3-reasons-why-vr-and-ar-areslow-to-take-off/. Accessed 5 Dec 2018.

Geise, S., \& Baden, C. (2015). Putting the image back into the frame: Modeling the linkage between visual communication and frameprocessing theory. Communication Theory, 25(1), 46-69.

Hanson, S., \& Yuan, H. (2018). Friends with benefits: Social coupons as a strategy to enhance customers' social empowerment. Journal of the Academy of Marketing Science, 46(4), 768-787.

Harmeling, C. M., Palmatier, R. W., Fang, E., \& Wang, D. (2017). Group marketing: Theory, mechanisms, and dynamics. Journal of Marketing, 81(4), 1-24.

Hartman, C. L., \& Kiecker, P. L. (1991). Marketplace influencers at the point of purchase: The role of purchase pals in consumer decision making. In 1991 AMA summer educators' conference proceedings (pp. 461-469). Chicago: American Marketing Association.

Hayes, A. F. (2013). Introduction to mediation, moderation, and conditional process analysis: A regression-based approach. New York: Guilford Press.

He, Z., Wu, L., \& Li, X. R. (2018). When art meets tech: The role of augmented reality in enhancing museum experiences and purchase intentions. Tourism Management, 68, 127-139.

Heller, J., Chylinski, M., de Ruyter, K., Mahr, D., \& Keeling, D. I. (2019). Let me imagine that for you: Transforming the retail frontline through augmenting customer mental imagery ability. Journal of Retailing, 95(2), 94-114.

Hennig-Thurau, T., Gwinner, K. P., Walsh, G., \& Gremler, D. D. (2004). Electronic word-of-mouth via consumer-opinion platforms: What motivates consumers to articulate themselves on the internet? Journal of Interactive Marketing, 18(1), 38-52.

Hewitt, P. L., Flett, G. L., Sherry, S. B., Habke, M., Parkin, M., Lam, R. W., McMurtry, B., Ediger, E., Fairlie, P., \& Stein, M. B. (2003). The interpersonal expression of perfection: Perfectionistic selfpresentation and psychological distress. Journal of Personality and Social Psychology, 84(6), 1303-1325.

Hilken, T., de Ruyter, K., Chylinski, M., Mahr, D., \& Keeling, D. I. (2017). Augmenting the eye of the beholder: Exploring the strategic potential of augmented reality to enhance online service experiences. Journal of the Academy of Marketing Science, 45(6), 884 905.

Hilken, T., Heller, J., Chylinski, M., Keeling, D. I., Mahr, D., \& de Ruyter, K. (2018). Making omnichannel an augmented reality: The current and future state of the art. Journal of Research in Interactive Marketing, 12(4), 509-523.

Javornik, A. (2016). Augmented reality: Research agenda for studying the impact of its media characteristics on consumer behaviour. Journal of Retailing and Consumer Services, 30, 252-261.

Jeong, S. H. (2008). Visual metaphor in advertising: Is the persuasive effect attributable to visual argumentation or metaphorical rhetoric? Journal of Marketing Communications, 14(1), 59-73.

Jiang, Y., Adaval, R., Steinhart, Y., \& Wyer, R. S., Jr. (2014). Imagining yourself in the scene: The interactive effects of goal-driven selfimagery and visual perspectives on consumer behavior. Journal of Consumer Research, 41(2), 418-435.

Keeling, K., Keeling, D., \& McGoldrick, P. (2013). Retail relationships in a digital age. Journal of Business Research, 66(7), 847-855.

Kim, Y., Sohn, D., \& Choi, S. M. (2011). Cultural difference in motivations for using social network sites: A comparative study of American and Korean college students. Computers in Human Behavior, 27(1), 365-372.

King, R. A., Racherla, P., \& Bush, V. D. (2014). What we know and don't know about online word-of-mouth: A review and synthesis of the literature. Journal of Interactive Marketing, 28(3), 167-183.

Kirmani, A., \& Campbell, M. C. (2004). Goal seeker and persuasion sentry: How consumer targets respond to interpersonal marketing persuasion. Journal of Consumer Research, 31(3), 573-582.

Kolsarici, C., \& Vakratsas, D. (2018). Synergistic, antagonistic, and asymmetric media interactions. Journal of Advertising, 47(3), 282-300.

Koopman, J., Lanaj, K., \& Scott, B. A. (2016). Integrating the bright and dark sides of OCB: A daily investigation of the benefits and costs of helping others. Academy of Management Journal, 59(2), 414-435.

Mathmann, F., Chylinski, M., de Ruyter, K., \& Higgins, E. T. (2017). When plentiful platforms pay off: Assessment orientation moderates the effect of assortment size on choice engagement and product valuation. Journal of Retailing, 93(2), 212-227.

Moe, W. W., \& Trusov, M. (2011). The value of social dynamics in online product ratings forums. Journal of Marketing Research, 48(3), 444456.

Mogilner, C. (2010). The pursuit of happiness: Time, money, and social connection. Psychological Science, 21(9), 1348-1354.

Newswhip (2017). Instagram video vs. photo: 7 surprising statistics on strategy. http://www.newswhip.com/2017/06/photo-vs-video-oninstagram/. Accessed 18 April 2018.

Oh, H. J., \& LaRose, R. (2016). Impression management concerns and support-seeking behavior on social network sites. Computers in Human Behavior, 57, 38-47.

Ouschan, R., Sweeney, J., \& Johnson, L. (2006). Customer empowerment and relationship outcomes in healthcare consultations. European Journal of Marketing, 40(9-10), 1068-1086.

Parker, J. R., Lehmann, D. R., \& Xie, Y. (2016). Decision comfort. Journal of Consumer Research, 43(1), 113-133.

Porter, M., \& Heppelmann, J. E. (2017). Why every organization needs an augmented reality strategy. Harvard Business Review, 95(6), 4657.

Pounders, K., Kowalczyk, C. M., \& Stowers, K. (2016). Insight into the motivation of selfie postings: Impression management and self-esteem. European Journal of Marketing, 50(9/10), 1879-1892. 
Poushneh, A. (2018). Augmented reality in retail: A trade-off between user's control of access to personal information and augmentation quality. Journal of Retailing and Consumer Services, 41, 169-176.

Prentice, C., Han, X. Y., \& Li, Y. Q. (2016). Customer empowerment to co-create service designs and delivery: Scale development and validation. Services Marketing Quarterly, 37(1), 36-51.

Ramsey, R. P., \& Deeter-Schmelz, D. R. (2008). An assessment of the psychometric properties of the style-of-processing (SOP) scale: How do we measure individuals' verbal/visual informationprocessing preferences? Journal of Marketing Theory and Practice, 16(1), 41-55.

Reich, W. (2011). The cooperative nature of communicative acts. Journal of Pragmatics, 43(5), 1349-1365.

Rosa, J. A., \& Malter, A. J. (2003). E-(embodied) knowledge and ecommerce: How physiological factors affect online sales of experiential products. Journal of Consumer Psychology, 13(1-2), 63-73.

Scholz, J., \& Duffy, K. (2018). We ARe at home: How augmented reality reshapes mobile marketing and consumer-brand relationships. Journal of Retailing and Consumer Services, 44, 11-23.

Scholz, J., \& Smith, A. N. (2016). Augmented reality: Designing immersive experiences that maximize consumer engagement. Business Horizons, 59(2), 149-161.

Schrader, D. C., \& Dillard, J. P. (1998). Goal structures and interpersonal influence. Communication Studies, 49(4), 276-293.

Semin, G. R., \& Smith, E. R. (2013). Socially situated cognition in perspective. Social Cognition, 31(2), 125-146.

Sezer, O., Gino, F., \& Norton, M. I. (2018). Humblebragging: A distinct-And ineffective - Self-presentation strategy. Journal of Personality and Social Psychology, 114(1), 52-74.

Smith, E. R., \& Collins, E. C. (2009). Contextualizing person perception: Distributed social cognition. Psychological Review, 116(2), 343364.

Townsend, C., \& Kahn, B. E. (2014). The "visual preference heuristic": The influence of visual versus verbal depiction on assortment processing, perceived variety, and choice overload. Journal of Consumer Research, 40(5), 993-1015.
Tuomela, R. (2007). The philosophy of sociality: The shared point of view. New York: Oxford University Press.

Villarroel Ordenes, F., Grewal, D., Ludwig, S., de Ruyter, K., Mahr, D., \& Wetzels, M. (2018). Cutting through content clutter: How speech and image acts drive consumer sharing of social media brand messages. Journal of Consumer Research., 45(5), 988-1012.

Wang, X., Yu, C., \& Wei, Y. (2012). Social media peer communication and impacts on purchase intentions: A consumer socialization framework. Journal of Interactive Marketing, 26(4), 198-208.

Wathieu, L., Brenner, L., Carmon, Z., Chattopadhyay, A., Wertenbroch, K., Drolet, A., Gourville, J., Muthukrishnan, A. V., Novemsky, N., Ratner, R. K., \& Wu, G. (2002). Consumer control and empowerment: A primer. Marketing Letters, 13(3), 297-305.

Wyer, R. S., Hung, I. W., \& Jiang, Y. (2008). Visual and verbal processing strategies in comprehension and judgment. Journal of Consumer Psychology, 4(18), 244-257.

Zeithaml, V. A., Berry, L. L., \& Parasuraman, A. (1996). The behavioral consequences of service quality. Journal of Marketing, $60(2), 31-$ 46.

Zhang, T., Agarwal, R., \& Lucas, H. C., Jr. (2011). The value of ITenabled retailer learning: Personalized product recommendations and customer store loyalty in electronic markets. MIS Quarterly, 35(4), 859-881.

Zhang, X., Li, S., \& Burke, R. R. (2018). Modeling the effects of dynamic group influence on shopper zone choice, purchase conversion, and spending. Journal of the Academy of Marketing Science, 46(6), 1089-1107.

Zhu, L., Benbasat, I., \& Jiang, Z. (2010). Let's shop online together: An empirical investigation of collaborative online shopping support. Information Systems Research, 21(4), 872-891.

Publisher's note Springer Nature remains neutral with regard to jurisdictional claims in published maps and institutional affiliations. 